\title{
Letramento acadêmico: percurso da construção da identidade profissional docente em Letras- Português em formação inicial
}

\author{
Selma Lúcia de Assis Pereira ${ }^{\star}$
}

\begin{abstract}
Resumo
O presente artigo tem como finalidade realizar uma reflexão sobre o percurso da construção da identidade profissional docente no curso de Letras-Português, em formação inicial, no Instituto Federal de Educação do Espírito Santo (Ifes) campus Venda Nova do Imigrante - ES, relacionando esse percurso com a formação acadêmica e o Estágio Supervisionado nos anos finais. Diante disso, partimos da problematização: que docente em Letras-Português o Ifes Campus Venda Nova do Imigrante espera formar? Para isso, discutimos à luz da fundamentação teórica baseada de autores diversos e partiu-se de reflexões sobre construção da identidade docente em formação inicial e humanização do Curso de Licenciatura em LetrasPortuguês em uma instituição tecnicista. Como percurso metodológico, realizou-se um acompanhamento dos relatos de experiências dos acadêmicos: foram selecionados dois relatos de experiência sobre o percurso do Estágio Supervisionado nos anos finais. Por fim, concluiu-se que, para que haja um processo formativo eficaz, espera-se um acompanhamento sistematizado do professor-orientador, professor-tutor e acadêmicos a fim de que possam iniciar um percurso de identidade profissional docente.

Palavras-chave: Identidade profissional docente. Formação docente inicial. Letramento. Relato de experiência. Estágio Supervisionado.
\end{abstract}

* Pontifícia Universidade Católica de Minas Gerais (PUC Minas). Doutoranda em Linguística e Língua Portuguesa. ORCID https://orcid.org/0000-00021853-8920.

Cadernos CESPUC de Pesquisa. Série Ensaios. n.39, $2^{\circ}$ Sem./2021, p. 167-184. e-ISSN: 2358-3231 (OJS). Recebido em: 10/11/2021. Aceito em: 14/12/2021. 


\title{
Academic Literacy: the path towards the construction of the professional identity of teachers in Portuguese Language in initial training
}

\author{
Selma Lúcia de Assis Pereira
}

\begin{abstract}
This article aims to reflect on the path of construction of the professional identity of teachers in initial training at the Federal Institute of Education of Espírito Santo (Ifes) campus Venda Nova do Imigrante - ES relating this path to academic training and the Supervised Internship in the final years. In view of this, we start with the question: what language teacher profile does the Federal Institute expect to train? In order to answer this question, our theoretical discussion is based of different authors and started with reflections on the construction of the teaching identity in initial training and humanization of the Licentiate Degree in Language Teaching in a technical institution. As methodological approach, we carried out a follow-up of the students' experience reports and we selected two experience reports from the discipline of the Supervised Internship in the final years. Finally, we conclude that, for there to be an effective training process, a systematic follow-up of the professor-advisor, professor-tutor and academics is expected, so that they may start a path of professional teacher identity.
\end{abstract}

Keywords: Teacher professional identity. Initial teacher training. Literacy. Experience report. Supervised internship. 


\section{Introdução}

Este estudo acadêmico pauta-se em uma investigação em curso que visa a refletir sobre o letramento dos relatos de experiência dos estudantes e acadêmicos do curso de Letras - Português, na disciplina de Estágio Supervisionado na etapa dos anos finais no Instituto de Educação Federal. Objetivou-se delinear como ocorre a construção da identidade profissional docente, em formação inicial, do Curso de Licenciatura em Letras - Português - do Instituto Federal do Espírito Santo (Ifes) campus Venda Nova do Imigrante. É importante apresentar o lugar em que está inserido o campus a fim de que se compreenda o contexto regional em que os acadêmicos e a comunidade acadêmica interagem. S i t u a m o nos em uma cidade interiorana, com pouco mais de 25 mil habitantes, em que a agroindústria familiar é uma potência. A cidade é reconhecida como a capital do agro-turismo pelo "Projeto Experiências do Brasil Rural", parceria entre os ministérios do Turismo (MTur) e da Agricultura, Pecuária e Abastecimento (MAPA), junto à Universidade Federal Fluminense (UFF). Dentro desse contexto, o campus oferece cursos técnicos de Ensino Médio - Administração e Agroindústria, Graduação - Curso de Bacharel em Administração, Curso de Bacharel em Ciências e Tecnologia dos Alimentos e Curso de Licenciatura em Letras-Português e uma Pós-graduação Lato Sensu em Educação e Práticas Educativas. O Curso de Licenciatura em Letras - Português iniciou-se no ano de 2016, sendo que a primeira turma a se formar foi em 2021. Na tentativa de buscar compreender como foi construída a identidade profissional docente em formação inicial, pretendemos, em nossa pesquisa, delinear o percurso formativo desses acadêmicos por meio dos relatos de experiência da disciplina do Estágio Supervisionado nos anos finais.

\section{Formação docente inicial - o estágio supervisionado}

Para iniciarmos esse estudo, indagamos sobre os seguintes temas: identidade profissional docente, formação inicial e estágio supervisionado. 
Diante disso, recorremos às leis que regulam o Estágio Supervisionado e que impactam em nosso trabalho.

$\mathrm{O}$ acadêmico ingressante no Curso de Licenciatura em LetrasPortuguês no IFES campus Venda Nova do Imigrante, a partir do $6^{\circ}$ período, inicia seu contato com as bases epistemológicas do Estágio Supervisionado Obrigatório cuja finalidade é prepará-lo para o fazer docente, conforme postula a Lei $\mathrm{n}^{\circ} 11.788$, de 25 de setembro de 2008 , que dispõe sobre o estágio de estudantes na graduação, compreendendo. A lei em seu art. $1^{\circ}$ indica: "Estágio é ato educativo escolar supervisionado, desenvolvido no ambiente de trabalho, que visa à preparação para o trabalho produtivo de educandos (...)". Pimenta e Lima (2013), em suas pesquisas, afirmam que o estágio nos cursos de formação de professores possibilita que os acadêmicos possam compreender a complexidade institucional em sala de aula, a fim de preparar a inserção desse futuro profissional em seu campo de trabalho/ atuação. A complexidade se dá por sermos sujeitos sócio-históricos culturalmente individualizados, com suas subjetividades, e nos formamos enquanto ser humano no coletivo em que estamos inseridos.

Em consonância, a Resolução do Conselho Nacional da Educação (CNE) nº 2, de 20 de dezembro de 2019, que define as Diretrizes Curriculares Nacionais para a Formação Inicial de Professores para a Educação Básica e institui a Base Nacional Comum para a Formação Inicial de Professores da Educação Básica (BNC - Formação), postula-se a "centralidade da prática por meio de estágios que enfoquem o planejamento, a regência e a avaliação de aula, sob a mentoria de professores ou coordenadores experientes da escola campo do estágio, de acordo com o Projeto Pedagógico do Curso (PPC)". (Art. 7, inciso VIII). Ainda se pontua, nesse artigo, no inciso VII, que é necessária "a integração entre a teoria e a prática, tanto no que se refere aos conhecimentos pedagógicos e didáticos, quanto aos conhecimentos específicos da área do conhecimento ou do componente curricular a ser ministrado". Pimenta e Lima (2013) afirmam que o papel das teorias estudadas nas áreas acadêmicas possui uma finalidade de iluminar e oferecer instrumentos e esquemas para análise e investigação que permitam ao acadêmico questionar sua realidade, dado que as teorias são explicações sempre provisórias da realidade.

Reiterando a Lei $n^{\circ} 11.788$ de 25 de setembro de 2008, o Conselho Superior do Instituto Federal do Espírito Santo estabeleceu a Resolução n ${ }^{\circ}$ 
58, de 17 de dezembro de 2018, que regulamenta os estágios dos alunos da Educação Profissional Técnica de Nível Médio e da Educação Superior do Instituto Federal de Educação, Ciência e Tecnologia do Espírito Santo (IFES), onde se destaca:

Art. $2^{\circ} \mathrm{O}$ estágio é considerado um ato educativo escolar supervisionado, desenvolvido no ambiente de trabalho, que visa à preparação para trabalho produtivo de educandos que estejam frequentando o ensino regular na Educação Profissional Técnica de Nível Médio e na Educação Superior, oferecido pelo Ifes nas modalidades presencial e a distância.

$\S 1^{\circ} \mathrm{O}$ estágio faz parte do projeto pedagógico do curso, além de integrar o itinerário formativo do educando.

$\$ 2^{\circ} \mathrm{O}$ estágio visa ao aprendizado de competências próprias da atividade profissional e à contextualização curricular, promovendo:

I. o relacionamento dos conteúdos e contextos para dar significado ao aprendizado; II. a integração à vivência e à prática profissional ao longo do curso;

III. a aprendizagem social, profissional e cultural para o desenvolvimento do educando para a vida cidadã e para o trabalho;

IV. a participação em situações reais de vida e de trabalho em seu meio;

V. o conhecimento dos ambientes profissionais;

VI. as condições necessárias à formação do aluno no âmbito profissional;

VII. a contextualização dos conhecimentos gerados no ambiente de trabalho para a reformulação dos cursos;

VIII. a inclusão do aluno com necessidades específicas no mercado de trabalho. $[\ldots]$

Percebem-se, neste contexto, as diretrizes para uma formação profissional técnica, para a preparação ao mercado de trabalho e com possibilidade para reflexão para reformulação dos cursos oferecidos pelo Instituto. Pimenta e Gonçalves (1992) consideram que a finalidade do estágio é propiciar ao aluno uma aproximação à realidade na qual atuará. Acredita-se que, ao se deparar com a comunidade escolar, agora não mais com um estudante da educação básica, o acadêmico poderá perceber que somente pela observação atenta da realidade é possível realizar uma intervenção pedagógica viável para os sujeitos que ali estão. Nesse sentido, o estágio curricular se caracteriza como uma atividade de conhecimento, 
de fundamentação, de diálogo e de intervenção na realidade, sendo, assim, objeto da práxis. Ou seja, é no contexto da sala de aula, da escola, do sistema de ensino e da sociedade que a práxis se dá (PIMENTA; LIMA, 2017). Dessa forma, a partir desses princípios, percebe-se o quanto é relevante o processo do Estágio Supervisionado na formação docente inicial e, consequentemente, no surgimento da identidade profissional docente.

\section{Formação docente inicial: um percurso a ser construído}

Ao refletirmos sobre a formação docente inicial, recorremos ao Projeto Curricular do Curso de Graduação estabelecido pela Instituição de Ensino Superior (IES). Há, nele, o direcionamento político e pedagógico na distribuição das disciplinas teóricas e pedagógicas. Alguns questionamentos surgem ao pensarmos nesse direcionamento: Como é construída a formação docente? Como podemos compreender se há o diálogo entre a teoria e a prática durante a formação docente? Este acadêmico(a) sente-se preparado(a) para assumir a complexidade da realidade da sala de aula?

Em meio às indagações, recorremos ao princípio básico, que é a formação docente inicial de um(a) futuro(a) professor(a). Para dialogar, trouxemos as reflexões de Gatti (2016). O autor que diz que a educação é prioritariamente um espaço onde pessoas com níveis desiguais compartilham seus conhecimentos. Ou seja, a escola proporciona a troca com o outro, a aprendizagem com o outro, na formação de um sujeito sócio-histórico-cultural, uma vez que prendemos coletivamente. Assim, ela afirma que "[...] a formação (docente) de quem vai formar torna-se central nos processos educativos formais, na direção da preservação de uma civilização que contenha possibilidades melhores de vida e co-participação de todos" (GATTI, 2016, p.163).

Em seguida, Gatti (2016) apresenta pressupostos a serem considerados para essa formação docente, como: a) fato educacional é cultural; b) o papel do professor é absolutamente central; c) o núcleo do processo educativo é a formação do aluno; d) a heterogeneidade cultural e social de professores e alunos e e) as práticas educativas institucionalizadas determinam, em grande parte, a formação de professores e, na sequência, 
de seus alunos. Ou seja, para cada pressuposto apresentado é imprescindível o (re)conhecimento do outro. Há necessidade de ir ao encontro da humanidade de ser docente em contraponto em estar docente. Gatti (2016, p. 163) considera que " compreender e discutir a formação, as condições de trabalho e carreira dos professores, e, em decorrência sua configuração identitária profissional, se torna importante para a compreensão e discussão da qualidade educacional de um país, ou de uma região."

Para Benevides (2006), a concepção de formação de professores está no seu processo reflexivo, o qual se dá na compreensão da realidade quando este(a) assume a sala de aula. De fato, para muitos acadêmicos o ato de assumir a responsabilidade de uma sala de aula é um desafio que o(a) deslocam para a uma incerteza do seu fazer pedagógico. Não quer dizer que os recém-graduados não estão aptos para o trabalho docente; quer dizer que estar diante de uma turma, planejar, expor-se, interagir e avaliar o processo de ensino-aprendizagem é um caminho de ir (responsabilidade) constante, é um ato de resistência e reflexão.

Nóvoa (1988) afirma que o docente precisa tomar consciência em seu saber, em seu discurso. O estudioso trata do conceito da reflexividade crítica que o docente constitui já em sua formação inicial. $\mathrm{O}$ trabalho de formação docente, para ele, pode ser construído a partir de suas vivências, por meio de sua trajetória de vida, refletindo em seu presente. Ou seja, o docente em sua formação inicial pode ser capaz de apreender os conceitos teóricos e refletir sobre suas intervenções pedagógicas para transformar sua realidade. Dessa forma, queremos compreender a identidade profissional docente em Letras, de formandos em um contexto tecnicista e profissionalizante como o Instituto Federal (If).

\section{Identidade profissional docente em formação inicial}

Em busca de realizar uma compreensão acerca da identidade profissional docente, recorremos ao conceito de identidade concebido por Hall (2003) e Bauman (1998; 2005), nas Ciências Sociais, para nos levar a refletir sobre o fazer docente que, por meio de um processo contínuo, (re) constrói-se, (re)define-se, (re)inventa-se. Somos sujeitos dialógicos e, por 
isso, necessitamos do outro para nos constituir, pautados no dialogismo e interacionismo (VOLOCHINOV, 2003) e na troca do eu e do outro como um ato de responsividade (BAKTHIN, 2003) na sala de aula.

É complexo tratar do tema identidade, no entanto a complexidade faz parte da essência da escola, do ser docente e do sujeito como indivíduo. Identidade, para Hall (2003), é concebida como uma ideia de ser integral, originária e unificada. Para Bauman (2005), identidade é uma construção líquida e fluida, instável, flexível e de muitas mudanças. Para ele, a identidade é uma construção de relações em suas negociações, do espaço e tempo quando se trata dos seus interlocutores e obviamente de seu contexto. $\mathrm{Ou}$ seja, quer um espaço melhor que a sala de aula para experimentarmos essas complexidades? O docente em formação contínua percebe essas transformações e busca se adaptar, construindo o seu percurso de identidade profissional docente.

Dessa forma, compreendemos que a identidade é construída paulatinamente, de acordo com o seu contexto sócio-histórico-cultural a partir de sua posição enquanto sujeito em diversos e diferentes movimentos (HALL, 2003). Diante disso, é desafiador conceber o que seja uma identidade profissional docente, por se tratar de algo marcado por diversos atravessamentos que compõem a lida do profissional da educação. Moita Lopes (2002) traz o conceito da construção da identidade social, que está relacionado ao indivíduo e a seu comportamento discursivo, porque esse comportamento é (re)construído e dialógico. Isto significa que definir uma identidade profissional docente, no contexto de mudanças frequentes, de (des)construção de paradigmas, de reflexão do fazer pedagógico com a sociedade atual é uma construção processual e não taxativa.

\section{Universo tecnicista do Instituto Federal}

A Resolução do Conselho Superior (CS), no 49, institui o Plano de Desenvolvimento Institucional (PDI) para o período 2019/2 - 2024/1, apresentado ao Ministério da Educação/Secretaria de Educação Profissional e Tecnológica, em sua apresentação afirma que 
O Ifes é maior do que parece. Nosso principal desafio é comunicar à sociedade tudo o que fazemos para promover educação profissional, científica e tecnológica pública de excelência, integrando de forma inovadora o ensino, a pesquisa e a extensão para construção de uma sociedade democrática, justa e sustentável, que é a missão organizacional deste Instituto (grifos nossos).

É interessante observar que, ao iniciar a apresentação do PDI, o leitor é convidado à afirmativa "O Ifes é maior do que parece", o que nos leva a pensar no trabalho de todos(as) os(as) agentes deste espaço de saber e dar respostas à sociedade de sua importância. Outro ponto é direcionar em sua missão a promoção profissional, científica e tecnológica de excelência. Assim, indagamo-nos: "e as licenciaturas instauradas nesse espaço profissionalizante?". Torna-se um percurso a ser discutido com a comunidade acadêmica para ampliar a visibilidade da formação inicial desses sujeitos-profissionais à sociedade.

É relevante mencionar que o modelo de planejamento é pautado como estratégico e participativo a partir dos seguintes princípios

Art 30:

1. compromisso com a justiça social, equidade, cidadania, ética, preservação do meio ambiente, transparência e gestão democrática;

2. verticalização do ensino e sua integração com a pesquisa e a extensão;

3. eficácia nas respostas de formação profissional, difusão do conhecimento científico e tecnológico e suporte aos arranjos produtivos locais, sociais e culturais; 4. inclusão de pessoas com deficiências e necessidades educacionais especiais;

5. natureza pública e gratuita do ensino, sob a responsabilidade da União (INSTITUTO FEDERAL DO ESPÍRITO SANTO, 2009).

Ao lermos o item 2, que trata da verticalização do ensino, compreendemos que há uma abertura para o Ifes ofertar graduação e pósgraduação, como as universidades. Por ser uma instituição tecnicista e profissionalizante, os cursos de graduação são, em sua maioria, bacharelados para atender à demanda de mão de obra onde quer que esteja inserido o campus. Dessa forma, as licenciaturas são ofertadas por alguns campi do Ifes, fazendo-nos refletir em que medida a concepção de identidade profissional docente é construída neste espaço profissionalizante. 


\section{Humanização no curso de licenciatura no contexto do Instituto Federal de Educação, Ciência e Tecnologia}

Para traçar um pensamento sobre a humanização na licenciatura, primeiro apresentamos a concepção da missão do Instituto Federal (If) que demonstra um perfil tecnicista e profissionalizante. Segundo Rosa (2005), “[...] os Institutos Federais possuem vasta experiência no ensino profissionalizante técnico e tecnológico, mas ainda não amadureceu uma concepção de formação de professores [...]". Somente em 2008, com a lei $\mathrm{n}^{\circ} 11.892$, foi instituída aos Ifs a criação das licenciaturas. Nessa criação, Rosa (2005) aponta que houve a necessidade de uma mudança qualitativa do quadro pessoal do Ifs, ofertando concursos públicos para licenciados e pedagogos, favorecendo as discussões nos processos de ensinoaprendizagem, na formação dos docentes do Instituto e dos discentes tanto do ensino médio quanto da licenciatura. Essa mudança real constituiu uma concepção trazida por Freire (1996), que trata da ação-reflexão-ação dos sujeitos, por meio de sua conscientização, de sua prática humana. Freire (1996, p. 92) diz que "Como prática estritamente humana jamais pude entender a educação como uma experiência fria, sem alma, em que os sentimentos e as emoções, os desejos, os sonhos devessem ser reprimidos por uma espécie de ditadura racionalista”. Em outras palavras, não somos máquinas, não estamos neste mundo apenas para apertar parafusos, distantes de nossos sentimentos. Há vida pulsante.

Neste lugar, a humanização do profissional docente, em sua formação inicial, constitui-se em uma luta permanente e fundamental. Rosa (2005) nos aponta um caminho: “[...] percebemos a necessidade de espaços de formação para o atendimento dos diferentes níveis da educação como meio para a profissionalização docente [...]", a autora completa dizendo que, "Consequentemente, o docente que atuará na formação docente dos futuros profissionais imprimirá uma identidade profissional mais humanizadora e dialógica”. 

de fala

Durante o período realizado, percebemos, na disciplina curricular de Estágio Supervisionado - anos finais -, ocorrida no $6^{\circ}$ período, que havia uma necessidade de maior aproximação entre a escola, a academia e os acadêmicos. Por isso, realizamos uma sistematização de acompanhamento nas escolas onde os estudantes de Letras - Português fizeram seus estágios. Ao serem encaminhados para as escolas, de acordo com os procedimentos pautados pela legislação, os acadêmicos chegavam às salas de aula da graduação com vontade de expressar suas vivências nas escolas, expor suas observações, seus receios e suas ideias. Dessa forma, humanizamos esses momentos com o que chamamos de "Estágio Terapia", que acontecia às sextas-feiras nas últimas aulas da semana. Um momento intenso que raramente havia faltas.

A partir desse momento, os relatos orais eram valorizados pelos colegas, que prestavam muita atenção: havia comentários, sugestões e muita partilha. Os acadêmicos lembravam-se de momentos das aulas dos seus professores na graduação para pensar nas intervenções. Percebiam que aliar a teoria à prática, como proposta de Pimenta e Lima (2017), era um desafio devido às realidades de cada escola.

Posteriormente, os acadêmicos produziam relatos de experiências para fins de registro e publicação. Esse letramento acadêmico é importante para constituir estudos e pesquisas a fim de aprimorarmos as estratégias durante o percurso da construção da identidade profissional docente. Como afirma Fischer (2007), "é no meio acadêmico que sua produção intelectual - leitura, oralidade e escrita - deve se adequar às formalidades e exigências solicitadas".

É importante ressaltar que a cidade de Venda Nova do Imigrante não possui muitas unidades de ensino fundamental da etapa dos anos finais. São aproximadamente três escolas na região central e as demais ficam na zona rural. A princípio, houve uma conversa da professora-orientadora com a equipe pedagógica de cada escola para o aceite dos estagiários. Posteriormente, fizemos encontros com os professores-tutores a fim de explicar a dinâmica do acompanhamento e, só depois, encaminhamos 
os acadêmicos-estagiários. A experiência do Estágio Supervisionado transformou o ambiente da escola, como também dos acadêmicos e do Ifes. Um acadêmico-estagiário, em suas considerações finais do relato de experiência, afirma que

Após a realização do estágio supervisionado, foi possível perceber o tamanho da responsabilidade do trabalho docente. Conduzir o processo de aprendizagem é desafiador, complexo e requer constantes estudos, formações e a reflexão de sua prática na sala de aula.

Pude notar que os novos estudos que falam sobre o trabalho com gêneros textuais nas aulas de Língua Portuguesa apresentam-se como uma metodologia eficaz para o ensino de língua materna. Nossa sequência didática abordou o gênero Memórias Literárias e Fotografia possibilitando um diálogo entre a língua escrita e a linguagem visual, ambas completando-se e construindo uma mensagem comunicativa, significativa, no contexto escolar.

A proposta também objetivou e conseguiu trabalhar na afetividade dos alunos com sua escola e, consequentemente, no relacionamento entre todo o corpo profissional da instituição. $\mathrm{O}$ texto produzido também serviu como diagnóstico e apontou caminhos para trabalhar diversas áreas da escrita nas aulas futuras.

Constatamos que a inserção da fotografia na proposta de produção do textual funcionou como um instrumento potencializador para a prática da escrita, gerando motivação e interação. Os alunos sentiram-se mais motivados em escrever e curiosos durante todo o processo. Além disso, a prática, em sua particularidade, gerou envolvimento entre os alunos e a escola em si e com os funcionários do corpo pedagógico/gestor e administrativo da instituição.

Por fim, podemos considerar que planejar, executar e finalizar uma proposta como essa exige dedicação, tempo, disposição, pois é necessário trabalho fora do horário de expediente. Porém, são práticas assim que geram envolvimento, afetividade, integração e acima de tudo e o mais importante ajudam na construção do conhecimento (PETERLE JÚNIOR,2020, p.51).

É relevante considerar que observar os relatos de experiências dos estagiários durante o percurso de formação inicial, na busca de compreender a construção do profissional docente em formação, é de muita responsabilidade. Percebemos o quanto nos é exigido planejamento, necessitando-nos (re)inventar, (re)criar, (re)novar. Como o processo de 
formação não se conclui com o término da graduação (PIMENTA, 2017) e porque somos sujeitos inacabados (BAKHTIN, 2003), para ser um profissional docente faz-se necessário compreender a complexidade da escola, de sua efervescência e dos acontecimentos das práticas sociais e culturais pulsantes neste espaço.

Marcelo (2009, p. 10) afirma que a formação docente por meio do estágio supervisionado "[...] deve [contribuir] para o desenvolvimento das suas competências profissionais através de experiências de diferente índole, tanto formais como informais". Isto mostra o quanto é importante a aproximação da teoria e prática na vivência do estágio supervisionado a fim de que o acadêmico possa desenvolver suas habilidades profissionais e iniciar seu percurso de identidade profissional docente. Conforme postula Pimenta (2017, p. 41), a "atividade docente é ao mesmo tempo prática e ação” - essa afirmativa é observada nas considerações finais do seguinte relato de experiência

Diante do exposto, consideramos importante ratificar que a vivência do estágio é uma experiência imprescindível, como anteriormente citado, pois permite aos estagiários conhecer a rotina da escola, a realidade dos professores e dos alunos, as práticas docentes, entre outros. A partir disso, podemos refletir sobre os métodos utilizados e aperfeiçoar as práticas pedagógicas futuras.

Salientamos que é por meio da reflexão que podemos repensar a prática. Consequentemente, começamos a criar nossa identidade como docente, isto é, passamos a elaborar o nosso próprio modo de ser, de fazer.

O estágio também é um momento oportuno para relacionar os conteúdos estudados na graduação com a prática vivenciada na escola, sob a supervisão do orientador. Dessa maneira, a construção de conhecimento do graduando tornase muito mais consistente tendo sido obtido a partir da união da teoria com a prática.

Cabe mencionar que também é uma experiência difícil e exigente visto que requer dedicação, planejamento e associação dos conteúdos teóricos às práticas. Além disso, percebemos que os desafios da profissão são inúmeros, entretanto, esperamos, por meio do trabalho e do estudo, colher bons frutos na carreira docente. (PIMENTEL, 2020, p.100). 
Ao dizer que "a vivência do estágio é uma experiência imprescindível [...] podemos refletir sobre os métodos utilizados e aperfeiçoar as práticas pedagógicas futuras", observa-se que há um esforço do futuro docente no qual ele refletirá sobre a realidade da escola, o que se aprende na graduação e o que é possível fazer em sua práxis.

Percebe-se, também, que a realidade das escolas públicas (municipais ou estaduais) é um grande desafio para o futuro docente frente às demandas exigidas pelo sistema educacional vigente. Mesmo assim, os futuros docentes possuem uma perspectiva esperançosa no fazer pedagógico, como menciona Freire (1992, p. 47), "Movo-me na esperança enquanto luto e se luto com esperança, espero".

Por fim, as considerações finais do relato de experiência abaixo emergem um indício de identidade profissional docente em formação inicial, ao declarar que

As percepções enquanto estagiária sobre a docência foram positivas, desafiadoras e condizentes com o momento vivenciado de estreia na docência. As percepções mais relevantes foram: quebra de paradigma de que os alunos/as são desinteressados em relação à escola; a descoberta de que o espaço escolar é rico em possibilidades e que, ao prepararmos uma aula, devemos sempre atentar para o protagonismo do/as aluno/as e incentivá-los para que se sintam envolvidos e sejam participantes da sua aprendizagem.

Por fim, constatei que ministrar uma boa aula e obter alto índice de participação é possível, desde que planejada, pensada, e que contenha atividades criativas, que incluam novas tecnologias e diferentes abordagens sobre o mesmo tema. É preciso que essa aula seja sempre conectada a questões sociais latentes aos alunos/ as, como no caso dessa sequência didática, que abordou no gênero debate regrado, o tema "gravidez na adolescência", utilizando um exercício da oralidade, tendo em vista a cidadania. (ARAUJO, 2020, p. 27).

Ao considerar suas percepções durante o estágio supervisionado no excerto acima, percebe-se que a futura docente buscou investigar a realidade em que ela estava inserida. Com esse olhar de investigadorapesquisadora. desenvolveu a intervenção pedagógica proporcionando o protagonismo dos alunos da escola. Pimenta e Lima (2017, p. 55) afirmam que o conhecimento por meio do estágio supervisionado envolve estudo, 
análise, problematização e proposição de soluções, como também estudos e pesquisas nesta área.

\section{Considerações finais}

Concluímos que se faz necessária uma ampla discussão da relação entre "teoria" e "prática" no entendimento trazido por Pimenta e Lima (2017) durante todo percurso da graduação, e não somente na disciplina curricular de Estágio Supervisionado. Esse diálogo fortaleceria o percurso da construção da identidade profissional docente em formação inicial. É preciso humanizar os Institutos Federais em seus cursos de licenciaturas proporcionando discussões e aproximações com as unidades escolares. Dessa forma, oportunizaremos não só um crescimento acadêmico, mas também profissional.

\section{Referências}

ARAUJO, Aleandra Ribeiro de. Práticas de oralidade em sala de aula: o debate regrado no exercício da comunicação e cidadania nas aulas de Língua Portuguesa. In: PEREIRA, Selma. L. A.; CALDAS, A. (org.). Estágio supervisionado em Letras: relatos de experiência no Ensino fundamental II. 1. ed. São Carlos: Pedro e João Editores, 2020. 27p.

BAKHTIN, M. M. Estética da Criação Verbal. São Paulo: Martin Fontes Editora, 2003.

BAUMAN, Zygmunt. Identidade. Rio de Janeiro: Jorge Zahar, 2005.

BAUMAN, Zygmunt. O mal-estar da pós-modernidade. Tradução de Mauro Gama e Cláudia Gama. Rio de Janeiro: Jorge Zahar Editor. 1998.

BENEVIDES, Araceli Sobreira. A formação de professores do curso de letras - aspectos para uma prática reflexiva. REVISTA LETRA MAGNA. Revista 
Eletrônica de Divulgação Científica em Língua Portuguesa, Lingüística e Literatura - ano 03- n. 05, $2^{\circ}$ sem./2006.

BRASIL. Lei n⿳ 11.788, de 25 de setembro de 2008, dispõe sobre o estágio dos estudantes dos Institutos Federais. Disponível em: http://www.planalto. gov.br/ccivil_03/_ato2007-2010/2008/lei/111788.htm Acesso em 01 nov. 2021.

BRASIL. Lei no 11.892, de 29 de dezembro de 2008, institui a Rede Federal de Educação Profissional, Científica e Tecnológica, cria os Institutos Federais de Educação, Ciência e Tecnologia. Disponível em: http://www. planalto.gov.br/ccivil_03/_ato2007-2010/2008/lei/111892.htm.

BRASIL. Ministério do Turismo. Disponível em: https://www.gov. $\mathrm{br} /$ turismo/pt-br/assuntos/noticias/ministerio-do-turismo-selecionaroteiros-para-o-projeto-experiencias-do-brasil-rural. Acesso em 01 nov. 2021.

BRASIL. Resolução Conselho Nacional da Educação (CNE) No 2, DE 20 de dezembro de 2019, define as Diretrizes Curriculares Nacionais para a Formação Inicial de Professores para a Educação Básica e institui a Base Nacional Comum para a Formação Inicial de Professores da Educação Básica (BNC-Formação). Disponível em: http://portal.mec.gov.br/docman/ dezembro-2019-pdf/135951-rcp002-19/file. Acesso em 01 nov. 2021.

FISCHER, A. A construção de letramentos na esfera acadêmica. Tese (Doutorado em Linguística) - Universidade Federal de Santa Catarina, Florianópolis, 2007. $340 \mathrm{f}$.

FREIRE, Paulo. Pedagogia da esperança: um reencontro com a Pedagogia do oprimido. São Paulo: Paz e Terra, 1992.

FREIRE, Paulo. Pedagogia do oprimido. 64. ed. Rio de Janeiro: Paz e Terra, 2017.

GATTI, B. A. Análise das políticas públicas para formação continuada no Brasil, na última década. Revista Brasileira de Educação. Rio de Janeiro: ANPED, v.13, n. 37, p. 57-70. 
GONÇALVES, C. L. e PIMENTA, S. G. Revendo o ensino de $2^{\circ}$ Grau, propondo a formação do professor. São Paulo: Cortez, 1992.

HALL, Stuart. A identidade cultural na pós-modernidade. 8. ed. Rio de Janeiro: DP\&A, 2003.

\section{INSTITUTO FEDERAL DO ESPÍRITO SANTO. Resolução Conselho} Superior $n^{\circ}$ 48, institui o Plano de Desenvolvimento Institucional (PDI) para o período 2019/2 - 2024/1. Disponível em https://www.ifes.edu.br/ images/stories/Res_CS_48_2019_-_PDI_-_Anexo.pdf Acesso em 01 nov. de 2021.

INSTITUTO FEDERAL DO ESPÍRITO SANTO. Resolução do Conselho Superior $\mathbf{n}^{\circ} 58$ de 17 de dezembro de 2018, regulamenta $\mathrm{o}$ estágio supervisionado. Disponível em: https://www.ifes.edu.br/images/ stories/-publicacoes/conselhos-comissoes/conselho-superior/2018/Res_ CS_58_2018_-_Regulamenta_Est\%C3\%A1gios_dos_alunos_do_Ifes.pdf Acesso em 01 nov. de 2021.

MARCELO, C. A identidade docente: constantes e desafios. Formação Docente, Belo Horizonte, v. 01, n. 01, p. 109-131, ago./dez. 2009.

MOITA LOPES, Luiz Paulo. Identidades fragmentadas: a construção discursiva de raça, gênero e sexualidade em sala de aula. Campinas: Mercado de Letras, 2002.

NÓVOA, Antonio. O passado e o presente dos professores. In: NÓVOA, Antonio (org.). Portugal: Porto, 1999.

NÓVOA, Antonio. Vidas de professores. 2. ed. Portugal: Porto, 1995. Acesso em 01 nov. 2021.

PETERLEJÚNIOR,Edézio. Relatode experiênciadoEstágioSupervisionado. In: PEREIRA, Selma. L. A.; CALDAS, A. (org.). Estágio supervisionado em Letras: relatos de experiência no Ensino fundamental II. 1. ed. São Carlos: Pedro e João Editores, 2020.51p.

PIMENTA, Selma Garrido; GONÇALVES, Carlos Luiz. Revendo o ensino de $2^{\circ}$ grau: propondo a formação de professores. Coleção Magistério - $2^{\circ}$ Grau. 2a. Ed. rev. Editora Cortez. São Paulo - SP. 1992. 
PIMENTA, Selma Garrido. Formação de professores: identidade e saberes da docência. In: PIMENTA, Selma Garrido (org.). Saberes pedagógicos e atividade docente. 4. ed. São Paulo: Cortez, 2005. p. 15-34.

PIMENTA, Selma. Garrido; LIMA, Maria Socorro. Estágio e docência. São Paulo: Cortez, 2017.

PIMENTEL. Viviana Leite. Trabalhando o gênero textual comentário articulado à obra $\mathrm{O}$ Pequeno Príncipe. In: PEREIRA, Selma. L. A.; CALDAS, A. (org.). Estágio supervisionado em Letras: relatos de experiência no Ensino fundamental II. 1. ed. São Carlos: Pedro e João Editores, 2020. $100 \mathrm{p}$.

ROSA, Ana Cláudia Ferreira. Desafios teóricos e metodológicos para a humanização da formação permanente de professores. Dissertação (mestrado) - Universidade de Santa Maria - Centro de Educação Programa de Pós-Graduação em Educação - RS - 2015.

VOLÓCHINOV, V. (Círculo de Bakhtin). Marxismo e filosofia da linguagem: problemas fundamentais do método sociológico na ciência da linguagem. Tradução, notas e glossário de Sheila Grillo e Ekaterina Vólkova Américo. São Paulo: Editora 34, 2017 [1929]. 